\title{
Clases medias chilenas y transgresión de la homogamia: una perspectiva histórica ${ }^{1}$
}

\author{
Oscar Mac-Clure $(*)$
}

\begin{abstract}
RESUMEN
En este trabajo estudiamos a las clases medias chilenas desde el punto de vista de procesos poco reflexivos de transgresión, que son relevantes cuando se enfrentan las desigualdades sociales desde la perspectiva de los propios individuos, como ocurre respecto de la homogamia. Un estudio histórico, desde el período post-colonial hasta hoy, nos permite caracterizar cómo ocurren estas transgresiones.
\end{abstract}

Palabras clave:

Clase media - crítica - transgresión - homogamia - desigualdad.

\begin{abstract}
In this paper we study the Chilean middle classes from the point of view of small reflexive processes of transgression, which are relevant when addressing social inequalities from the perspective of the individuals themselves, as for homogamy. An historical study, from the post-colonial period until today, allows us to characterize how these transgressions happens.
\end{abstract}

Keywords:

Middle class - critique - transgression - homogamy - inequality.

(*) Sociólogo y Doctor en Historia. Académico del Centro de Investigación Sociedad y Políticas Públicas, Universidad de Los Lagos, Santiago de Chile.

Artículo enviado el 31 de enero 2012. Aceptado por el Comité Editorial el 14 de mayo de 2012.

Correo electrónico: oscar.macclure@gmail.com

${ }^{1}$ La variable clases sociales (EGP) para las encuestas aplicadas en Chile, utilizada en este trabajo, fue elaborada por Vicente Espinoza, a quien agradezco sinceramente su apoyo. Mis agradecimientos también a Emmanuelle Barozet por sus rigurosos comentarios a este artículo. 


\section{Introducción}

En este artículo estudiaremos históricamente a las clases medias chilenas analizando en qué medida y cómo en las uniones de pareja se ha cuestionado la homogamia, la que incide de modo práctico en las desigualdades sociales.

Las transformaciones en la composición de los estratos medios, en sus oportunidades de movilidad social y en su identidad, han ocupado de modo preferente la atención de los estudios recientes sobre las clases medias en Chile y América Latina (Franco, León y Atria 2007, Franco y Hopenhayn, 2010, OECD, 2011). En estos estudios ha perdido relevancia el paradigma que en el pasado se interrogó sobre las clases medias como participantes en los conflictos de la sociedad, asignándoles un rol intermedio y finalmente subordinado a las posiciones conservadoras (Filgueira, 2001), una interrogante que retomaremos en este trabajo sin asignar un papel predefinido a estas clases.

Las desigualdades sociales han constituido históricamente un rasgo central de sociedades como la chilena y la latinoamericana, por lo que resulta de interés estudiar el cada vez más decisivo apoyo o rechazo de las clases medias a esta situación. En ciertos momentos históricos, en las clases medias chilenas han surgido posturas que han deslegitimado al sistema establecido, en particular, restando justificación a las desigualdades e injusticias sociales. Surge la interrogante de si ese discurso crítico ha tenido un correlato en el nivel de las interacciones entre individuos particulares, también importante de la vida social. Es decir, si ha habido comportamientos y prácticas habituales respecto de los que históricamente se ha expresado una no aceptación de desigualdades sociales o por el contrario, ha predominado una adaptación a la situación existente.

A nivel de la interacción cara a cara entre las personas, examinaremos la homogamia, uno de los modos de interactuar socialmente establecidos con influencia en la reproducción de las desigualdades. La homogamia se refiere al grado en que se establecen uniones de pareja o matrimonios entre personas con características socioeconómicas similares, como ingresos, educación, origen familiar o religión, entre otras, en una sociedad en particular.

La importancia actual de los vínculos conyugales en la desigualdad social ha sido puesta de relieve en estudios basados en datos cuantitativos acerca de la homogamia educacional en Chile y América Latina, según los cuales las personas establecen uniones de pareja con quienes tienen un similar nivel educacional, en una elevada proporción (Esteve \& McCaa, 2007; Torche, 2007). Las acentuadas e incluso categóricas diferencias entre las parejas según los niveles educacionales de los cónyuges, han dejado abierta la interrogante de si las clases sociales permiten una interpretación de esa homogamia educacional (Esteve \& McCaa, 2007, p. 79). Avanzaremos en esa línea de investigación, asumiendo que si la pertenencia a una clase social determina el acceso a recursos como el capital económico, la educación o el capital social y las distintas clases adoptan una práctica homógama, esto reforzaría barreras entre clases con diversos niveles de recursos, agudizando las desigualdades existentes. Desde 
esta perspectiva, la homogamia según clases sociales puede constituir un relevante objeto de transgresión, lo que amerita ser analizado en las clases medias.

Nuestro enfoque sobre esa forma de cuestionamiento se aproxima en un plano teórico al "giro neopragmático" (Celikates, 2006) introducido por Boltanski (2009), quien ha propuesto una teoría de la crítica que se centra en el punto de vista de los actores y de su propio sentido de justicia, en lugar de análisis estructurales o principios normativos. Esto ha sido desarrollado también desde los enfoques sociológicos de Beetham (1991) y Schwalbe, et. al. (2000), orientados a prestar atención y enfocar empíricamente los juicios de las personas respecto de la legitimidad y las justificaciones de lo establecido.

Con diversas conceptualizaciones, los sociólogos mencionados observan una primera forma de cuestionamiento que denominaremos "crítica", originada en una deslegitimación y consiguiente erosión de las reglas de justificación abiertamente instituidas o bien de una invalidación de su aplicación en la realidad, cuando "lo que es" se juzga que en los hechos no corresponde a "lo que debe ser". En un segundo nivel que denominaremos "transgresión", desarrollando lo planteado por los mismos sociólogos, puede gestarse un cuestionamiento relativamente irreflexivo, frente a procesos en alguna medida inconscientes que condicionan subjetivamente a las personas a adaptarse a lo establecido y a acatar lo prohibido, como si esto fuera algo natural o neutro. Si la legitimidad fundada en la posibilidad de un consenso a través de un diálogo racional (Habermas, 1987) es rechazada por la "crítica", utilizamos el término "transgresión" como una forma de deslegitimación normativa fuera del ideal de una argumentación estrictamente racional.

Sostenemos que estos procesos poco reflexivos de "transgresión" o violación de normas, desempeñan un papel particularmente relevante en el enfrentamiento de las desigualdades sociales desde la perspectiva de las propias personas de clase media, como ocurre respecto de la homogamia.

Consideramos de particular interés observar si hay pautas comunes respecto de cómo surgen las transgresiones de la homogamia en la clase media, más allá de qué se cuestiona, pues esto último se limita a eventos, contextos o procesos particulares, mientras lo primero permite plantearse una interrogante más genérica, abstracta y de fondo. En definitiva, nuestra interrogante apunta al grado en que la homogamia ha estado presente en las clases medias, en qué ha consistido esa regla y cuáles han sido sus efectos de diferenciación social, en qué medida eso ha sido cuestionado, pero sobre todo, cómo han ocurrido los procesos orientados a su transgresión. Esto se advierte nítidamente desde una perspectiva histórica, al estudiar los mecanismos propios de cada época y compararlos, en diversos períodos desde el post-colonial en el siglo XIX hasta el presente, como veremos en este artículo.

\section{Irreflexividad de las Transgresiones y Cuantificación}

Asumiendo que la homogamia en la constitución de parejas constituye un proceso de relativa irreflexividad, para su estudio resulta indispensable acceder a subjetividades latentes y recoger antecedentes cualitativos capaces de identificar procesos sutiles y 
tenues. Expandiendo las distinciones teóricas referidas a la "crítica" relativamente racionalizadora formuladas por los autores antes mencionados (Beetham, 1991; Schwalbe, et. al., 2000; Boltanski, 2009), distinguiremos si en el plano más irreflexivo de las "transgresiones", éstas apuntan directamente a las reglas homogámicas o más bien a su aplicación.

El cuestionamiento de lo establecido es un proceso dinámico, cuya mayor eficacia según Goffman (1974, pp. 487-488) y Boltanski (2009, p. 170), se alcanza cuando se abre paso desde las experiencias cara a cara cotidianas o en escenarios sociales específicos hacia la sospecha sobre las reglas y a la posibilidad de violarlas, generando una descomposición del marco contextual que ordena la distribución desigual de los recursos. Esto constituirá una guía para examinar cómo han ocurrido históricamente las transgresiones a la homogamia y en qué medida han apuntado a que pueden ser alteradas las propias reglas que definen la constitución de parejas.

En este trabajo nos apoyaremos en obras literarias y cinematográficas para el análisis de la homogamia en la conformación de las parejas, por tres razones principales. En primer lugar, porque abordan un tema del que habitualmente no se habla, excepto en espacios privados, que son retratados por ese tipo de obras. En segundo lugar, porque ofrecen una mirada aguda a un fenómeno elusivo a los intentos de observarlo. En tercer lugar, por una razón práctica: acerca de períodos cronológicamente más lejanos se carece de estudios sistemáticos sobre el tema que hayan sido producidos en su propia época.

Hemos seleccionado este material de acuerdo a criterios predefinidos: creaciones que permitan un examen acotado estrictamente a nuestros objetivos de estudio, suficientemente revisadas por la crítica cultural académica como para sustentar el análisis y finalmente, susceptibles de ser examinadas no sólo desde la perspectiva de la obra y su autor, sino también de la recepción por parte de sus destinatarios.

Aunque un análisis cualitativo es indispensable para nuestro objeto de estudio, las mediciones cuantitativas proporcionan una valiosa información que resume lo ocurrido a un gran número de personas. Respecto de épocas pasadas, se dispone de datos cuantitativos menos abundantes que en la época actual y fueron producidos con fines distintos a los que nos interesan en el presente. Nuestro método propende a maximizar la utilización de los datos cuantitativos disponibles y pertinentes acerca del pasado. Sin embargo, incluso en la actualidad, cuando hay mayor disponibilidad de estos datos, mantendremos una conexión consistente con la línea de análisis cualitativa.

Una de las mediciones cuantitativas más complejas para nuestro trabajo, se refiere al tamaño y composición de la clase media, contexto que resulta indispensable considerar para abordar la homogamia en esta clase. Siguiendo un criterio convencional en estudios sobre el tema, consideraremos que las clases medias están integradas por trabajadores no manuales. Parece una quimera abarcar bajo una misma etiqueta de "clase media" a una enorme diversidad de ocupaciones, niveles de 
ingresos, trayectorias vitales y estilos de vida, una heterogeneidad que se incrementa al aspirar a cubrir los cambios experimentados por miles de personas a lo largo de dos siglos y en contextos marcadamente diferentes. Sin embargo, los grandes números aportados por censos y encuestas nos permitirán resolver una parte importante de ese problema, sin caer en una sobresimplificación, pues enseguida utilizaremos esos datos cuantitativos como punto de partida para una comprensión más completa.

Los censos y datos de encuestas, tienen la ventaja de ofrecer valiosa información sobre la ocupación de las personas, para desde este punto de vista analizar cuantitativamente el desarrollo de las clases medias. Pero los datos históricos sobre las ocupaciones de las personas plantean varios desafíos metodológicos a resolver.

Uno de los problemas metodológicos más importantes consiste en que muchas de las ocupaciones de hace uno o dos siglos son muy diferentes a las actuales y otras simplemente ya no existen. Esto constituye una dificultad para elaborar comparaciones entre diversos períodos, como es de interés en nuestro estudio. Para enfrentar el problema, en este trabajo partimos de la clasificación de ocupaciones HISCO, desarrollada por un equipo de historiadores sociales europeos en base a estudios sobre el siglo XIX en Europa y Canadá (Van Leeuwen, Maas, Miles, 2002). HISCO integra las ocupaciones de esa época en la clasificación de la Organización Internacional del Trabajo (OIT) de 1968, que es compatible con la clasificación de 1988 actualmente en uso (OIT, 1991). La ventaja de proceder de ese modo consiste en que la clasificación OIT-68 mantuvo cientos de ocupaciones identificadas en épocas pasadas. Las categorías HISCO sustentadas en la OIT-68, nos facilitan establecer equivalencias con la clasificación OIT de "tipos de ocupación" u oficios, la Clasificación Internacional Uniforme de Ocupaciones CIUO-88. Esto nos permite disponer de categorías homogéneas respetando las particularidades de ocupaciones específicas en diversos períodos históricos.

Disponiendo de una clasificación ocupacional homogénea, la siguiente dificultad consiste en agrupar las ocupaciones específicas distinguiendo diversos estratos de clases medias y las restantes clases sociales. Para estos efectos, utilizaremos la escala de estratificación social de Erikson y Goldthorpe (1993), una de las más aplicadas a nivel internacional y en los estudios recientes más relevantes sobre estratificación en Chile (Torche y Wormald, 2004; Espinoza y Barozet, 2008). En lo que dice relación con las clases medias, esta escala diferencia estratos según el criterio de la prestación de servicios con mayor o menor autonomía, distinguiendo entre las categorías de Servicios por un lado y las de Rutinas No-manuales por otro. Adicionalmente, en la escala se distinguen dos clases de acuerdo al criterio de propiedad y control de los medios productivos, los pequeños propietarios y los trabajadores independientes, que también consideraremos parte de las clases medias. De este modo, dependiendo de la disponibilidad de datos, más limitados al alejarnos en el tiempo, utilizaremos una definición única de los diversos estratos de las clases medias desde el punto de vista ocupacional, pero lo suficientemente flexible para considerar las particularidades históricas de las ocupaciones. 
Abordando de este modo el desafío metodológico de utilizar de modo homogéneo los datos cuantitativos censales y de encuestas recientes, dividiremos la historia de los dos siglos desde la independencia del imperio español hasta hoy, en períodos que poseen rasgos comunes que los diferencian respecto de los demás. De acuerdo a un relativo consenso en el mundo académico, distinguiremos tres grandes períodos: la etapa post-colonial, el período de la matriz "clásica" desde alrededor de 1920 y la etapa iniciada por la dictadura militar impuesta en 1973.

\section{El período post-colonial y la transgresión de la homogamia para el ascenso social}

Al ocurrir la independencia del imperio español, la mayor parte de la población de Chile habitaba en zonas rurales y realizaba actividades agrícolas o ganaderas. Sólo un $9 \%$ residía en las seis mayores ciudades del territorio (Johnson, 1978), donde podemos considerar que en las décadas siguientes emergió una clase media, siguiendo el criterio convencional que las define como un conglomerado básicamente urbano.

Tomando como referencia el caso de Santiago, la mayor ciudad del país, el Gráfico 1 permite apreciar el tamaño y composición de las clases sociales y las clases medias en particular, en 1875.

\section{Gráfico 1. Clases sociales según ocupación en Santiago, 1875}

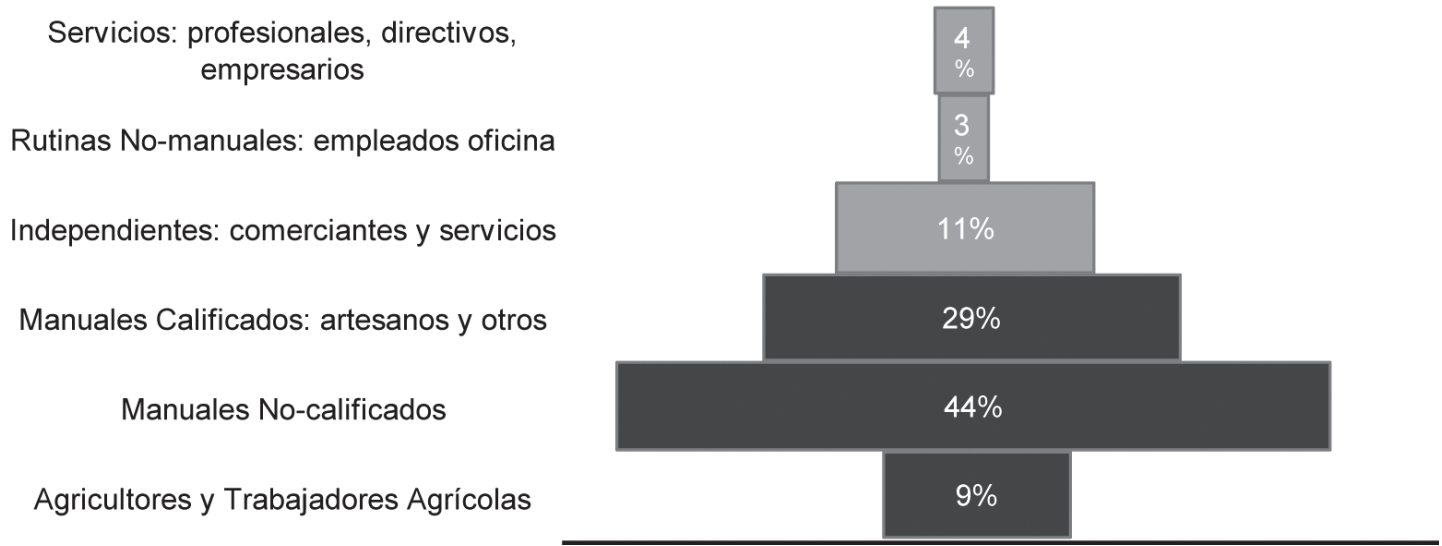

Fuente de los datos: Censo 1875.

De acuerdo a los datos censales de la ciudad de Santiago, 75 mil personas declararon una ocupación en el censo de 1875, en una población total de 195 mil personas. Los estratos más numerosos correspondían a los trabajadores manuales, tanto los Calificados como los No-calificados, según se aprecia en el Gráfico 1, quienes se distinguían de los Agricultores y Trabajadores Agrícolas que residían en la ciudad.

Al mismo tiempo, empezaba a emerger una clase media que se aprecia en los tres estratos superiores del gráfico. El estrato de Servicios, constituido por profesionales como los abogados, directivos y empresarios, abarcaba un $4 \%$ de las ocupaciones y era el más cercano a la pequeña clase alta que constituía la élite en el poder y controlaba la economía, pero la parte más numerosa de este estrato estaba integrada por profesores 
y preceptores de enseñanza primaria, farmacéuticos, fabricantes de alimentos, matronas y otras profesiones que pueden ser consideradas de clase media. La clase de Rutinas No-manuales integrada por empleados de oficina y otros, abarcaba a un $3 \%$ de los empleos. El numeroso estrato de Independientes que se desempeñaban en el comercio y los servicios, incluía un pequeño sector formal integrado por quienes pagaban patentes municipales, el cual representaba otro 3\% del total de ocupaciones ${ }^{2}$ y se aproximaba a un perfil típico de clase media. Sumando estos tres estratos, las clases medias abarcaban cerca de un 10\% de la ocupación en la ciudad.

Cabe destacar que nuestros datos cuantitativos sobre el tamaño de las clases medias tenían alguna asociación con percepciones de la propia época acerca de la existencia de estas clases. Un cronista de esos años relató que en el partido conservador o pelucón en Santiago participaban numerosas personas pertenecientes a sectores intermedios diferenciados de la clase alta y los artesanos, a través de una organización compuesta por " (...) tres secciones: la primera, de personas importantes; la segunda, de individuos de menos categoría; y la tercera, de artesanos" ${ }^{\prime \prime}$. Otra crónica coetánea describió modos de sociabilidad que distinguían a la clase media en las formas de celebración de su día de nacimiento o de su santo: "Cada clase la celebra a su manera: la jente de tono con una comida o un baile, jeneralmente; la clase media con una tertulia o remolienda con cauceo y el pueblo con una rasca"4. Más adelante en el mismo siglo XIX, un partidario del derrocado presidente Balmaceda escribió un poema formulando un llamado político y social a la clase media, cuyos versos se iniciaban con ${ }^{5}$ :

\section{"¡Arriba, Clase Media!}

¡Sacude tu letargo!"

Para estas clases medias, el matrimonio y las uniones de pareja constituían un asunto de relevancia, de un modo particular. Estos vínculos asumieron en los estratos medios formas diferentes a los lazos establecidos en otras clases sociales, como se puede apreciar al comparar las particularidades de éstos en las diferentes clases, como examinaremos enseguida.

En el pequeño número de familias de clase alta que ejerció el poder en Chile durante el siglo XIX, está ampliamente documentada la presencia de una marcada homogamia en los matrimonios (Balmori and Oppenheimer, 1979;Balmori, Voss y Wortman, 1990; Cavieres y Salinas, 1991; Vicuña, 2010). En el trabajo de Oppenheimer (Balmori and Oppenheimer, 1979), uno de más completos sobre el tema, fueron estudiadas veinticuatro familias chilenas de clase alta durante el siglo XIX a lo largo de varias generaciones. Los integrantes de esta clase se casaban con elevada frecuencia entre ellos, predominando así un principio de homogamia en la elección de cónyuge, como ocurría en la mayor parte de América Latina. Lo importante consiste en que los matrimonios entre personas socialmente cercanas permitían establecer y ampliar

\footnotetext{
${ }^{2}$ Las patentes municipales en la ciudad fueron 2.590 en 1870. En: Tornero, Recaredo. Chile ilustrado. Valparaíso, El Mercurio, 1871 p. 102

${ }^{3}$ José Zapiola, Recuerdos de treinta años, Santiago, Zig-Zag, 1945 (1ª . Edición 1874), p. 159.

${ }^{4}$ Julio Chaigneau, "Los santos", La semana, Santiago, 25 de septiembre de 1875, No. 25, citado por Foresti, Löfquist y Foresti (2001, p. 153)

5 Juan Rafael Allende, "A la clase media", 1893, citado por Subercaseaux (1997, p. 65).
} 
un sistema de parentesco y de alianza, fortaleciendo y expandiendo las redes de poder social, económico y político. La aplicación de este principio de homogamia constituía una base fundamental para la mantención y ampliación de las condiciones de dominación de la clase dirigente. Más allá de este efecto visible, contribuía a naturalizar simbólicamente las diferencias sociales, bajo la apariencia de un destino enraizado en la vida de las personas y no susceptible de ser modificado (Vicuña, 2010).

Continuando con nuestros referentes de comparación, a diferencia de la clase alta, se ha sostenido que en las relaciones afectivas de las familias populares, principalmente del sector mayoritario integrado por quienes vivían en los ranchos o chozas de las haciendas, predominaban las uniones consensuales o informales pero ilícitas, como las relaciones sexuales por parte de hombres y mujeres solteros, la convivencia de hecho en forma de amancebamiento o concubinato y el adulterio, transgrediendo la doctrina y las normas de la religión católica, predominante en la sociedad de la época (McCaa, 1983; Cavieres y Salinas 1991; Goicovic, 2006). Más aún, registros parroquiales muestran que las relaciones de consanguineidad eran frecuentes, en grados de parentesco prohibidos por la ley eclesiástica (McCaa, 1983). Esto último merece especial atención: los padrones censales originales aplicados en 1854 en diversas haciendas de las zonas de Los Andes y Petorca, permiten conocer los apellidos de los cónyuges que encabezaban cada hogar y como resultado del análisis, se aprecia una frecuente repetición de los mismos apellidos en cada hacienda, un indicador de relaciones conyugales con un cierto grado de consanguineidad ${ }^{6}$. A modo de ilustración, en una de las haciendas, los 72 hogares de los inquilinos o trabajadores agrícolas eran encabezados por 134 hombres y mujeres, cuyo primer apellido se repetía al menos cuatro veces en un $44 \%$ de estas personas. Estas relaciones homogámicas podrían explicarse por el relativo aislamiento geográfico de quienes habitaban en las haciendas y por su carácter funcional al apoyo mutuo para la subsistencia en las precarias condiciones del campo. Los trabajadores agrícolas constituían el sector mayoritario de la población chilena, de modo que la extendida homogamia en el mundo rural tenía relevancia en el conjunto de la sociedad.

Comparando con las dos clases que hemos examinado, se hacen patentes particularidades de la clase media que de otro modo serían menos visibles. En la clase media, a diferencia de las otras, eran poco frecuentes los apellidos repetidos, al examinar a los jefes de hogar de Concepción y sus cónyuges, según se desprende de los padrones censales de 1854 en uno de los cuatro sectores en que se subdividía la ciudad $^{7}$. En un sentido más amplio, esos matrimonios sin indicios de algún grado de consanguineidad, lo que no significa sin reprocidad, muestran que el mundo urbano favorecía intercambios más distantes que en las zonas rurales.

En la nueva clase media surgida en el período post-colonial del siglo XIX, el rasgo predominante no consistía en una homogamia marcada por relaciones de parentesco en algún grado, como ocurría en la clase alta y entre los mayoritarios trabajadores agrícolas. Un "capital cultural" compartido tampoco constituía un factor de

\footnotetext{
${ }^{6}$ Archivo Nacional, Fondo Gobernación Los Andes, Vol. 60. Archivo Nacional, Fondo Gobernación Petorca, Vol. 21.

${ }^{7}$ Archivo Nacional, Fondo Intendencia Concepción, Vol. 418 y 422.
} 
homogamia en este nuevo estrato, si se considera su diversidad respecto de saber leer y escribir, como acaecía en Concepción según los mismos padrones censales: la mitad de los jefes de hogar de clase media sabía leer y escribir pero la otra mitad era analfabeta y había también una diversidad de situaciones entre los cónyuges, pues a veces el hombre era letrado pero no la mujer o a la inversa.

Recursos económicos tales como medios de producción agrícolas o mineros, activos comerciales o financieros, inmuebles urbanos e incluso predios rústicos cultivables o urbanizables, constituían lejos la más ventajosa fuente de ingresos, en gran medida fuera del alcance para la naciente clase media. Esto último se debía en parte a que las clases medias estaban excluidas de las uniones matrimoniales con la clase alta, cuyos vínculos conyugales constituían un mecanismo de transmisión de las propiedades y de reproducción de posiciones sociales entre una generación y otra.

Enfrentando esta situación y teniendo como base su propio menor grado de homogamia, atenuar las barreras homogámicas de la clase alta parece haber sido una aspiración en la clase media durante esos años, como expondremos a continuación. Esto puede ser evocado a partir de un ejemplo literario que ha sido ampliamente utilizado como fuente documental para describir la época, la novela Martín Rivas de Alberto Blest Gana, publicada en 1862. Tanto desde la crítica literaria académica como desde la historiografía, se ha abierto una discusión sobre la corriente literaria y la ideología de la que formaba parte el autor, acerca de si el protagonista Martín Rivas pertenecía a una incipiente clase media o a un sector de la clase dominante, sobre cuáles eran los nuevos valores que propugnaba y si efectivamente había un sentido crítico en la novela (Barr-Melej, 2001; Concha, 2006; Goic, 1968, Engelbert, 2000; Foresti, Löfquist y Foresti, 2001; Guerra, 1987, Jocelyn-Holt, 1999; Melfi 1938, Silva Castro, 1955; Subercaseaux, 1997). Con las debidas precauciones derivadas de utilizar un texto literario, Martín Rivas también puede ser leído de modo específico como una identificación de situaciones posibles de intercambio matrimonial y sobre las alternativas de decisión disponibles.

En la novela, situada en 1851 pero publicada en 1862, lo que estaba en juego era la heterogamia social en la elección de pareja, en torno a la fábula troncal del proceso amoroso de Martín, familiarmente empobrecido y provinciano, con la elegante y santiaguina Leonor. El horizonte para el protagonista no consistía tanto en una movilidad social intergeneracional, pues su padre había sido antes un próspero empresario minero. Mas bien, desarrollando lo planteado por Jocelyn-Holt (1999, p. 36), el capital cultural, expresado en el "talento" de Martín, adquiría un peso similar al capital económico representado en la fortuna de la familia de Leonor, lo que justificaba realizar sobre esa base una alianza matrimonial que mantuviera o acrecentara el capital social familiar. La ironía presente en la novela (Foresti, Löfquist y Foresti, 2001) no cuestionaba la regla de homogamia en sí misma, sino que consistía en una burla sutil respecto de la forma de aplicar la regla, proponiendo un transgresor menor grado de estrechez en las delimitaciones de clase social y en la influencia parental para el vínculo matrimonial. Lo anterior marcaría un giro en comparación con la generación anterior. 
En un plano paralelo y opuesto, se desarrollaba la historia satirizada (Goic, 1968, Foresti, Löfquist y Foresti, 2001) de la relación de Agustín, hermano de Leonor, con la joven Adelaida. Esta última pertenecía a una familia de "medio pelo", es decir, a la nueva clase media-baja (Barr-Melej, 2001, p. 81). La familia, encabezada por su madre viuda y analfabeta, contaba con una sirviente y había recibido de su padre, un comerciante, una herencia valorada en ocho mil pesos, un monto no menor si se considera que en un barrio de la ciudad como donde vivían, una casa modesta pero de material sólido podía ser transada en mil a dos mil pesos ${ }^{8}$. Se trataba del prototipo de la nueva clase media que emergía, integrada mayoritariamente por comerciantes medianos y pequeños, marginales respecto de la clase alta, pero en una posición superior a la del comercio ambulante. La novela abordaba la demanda de heterogamia social en la conformación del matrimonio, un mecanismo de movilidad ascendente para la nueva clase media integrada por Adelaida y su familia de "medio pelo". Esta aspiración, contraria a la regla de homogamia establecida, era rechazada por la clase alta y fue satirizada por Alberto Blest Gana.

En contraste, otra hija de la viuda de clase media, Edelmira, a pesar de amar a Martín aceptó y apoyó con sacrificio de sí misma y con una bondad sumisa, el enlace conforme a la regla de homogamia entre el protagonista y Leonor.

En la estructura narrativa, la historia troncal de Martín y Leonor proponía una flexibilización en la aplicación de la regla de homogamia, mientras la historia de Agustín y Adelaida, al ser satirizada por el autor y finalmente desbaratada por el protagonista de la novela, proporcionó una argumentación que bloqueaba una heterogamia favorable al ascenso de miembros de la clase media. Esto es observado por uno de los más destacados críticos literarios de la novela: "el talento de Martín no es otro que (...) aplicar la ley de las valencias sociales para crear compuestos amorosos legítimos" (Concha, 2006, p. 31). La extraordinaria popularidad de Martín Rivas en su propia época (Barros Arana, 1875; Goic, 1968) estuvo asociada a esa trama donde la regla de homogamia constituía un asunto central. ¿Cuál es la explicación de la extraordinariamente favorable recepción en el público lector? ¿Había un nexo entre los lectores y las clases medias? ¿Por qué tuvo éxito el conflictivo entretejido homogámico-heterogámico de la narración? ¿Cómo se entroncó en el imaginario de la sociedad de ese tiempo? La respuesta no se encuentra sólo en la estructura del texto y el contexto de producción de la novela, sino que requiere estudiar el contexto de recepción, identificando al lector hacia el cual fue dirigido el discurso narrativo y el mecanismo del exitoso pacto de lectura del autor con el público lector.

Una clave del contexto de recepción de esa historia conflictiva en torno a la homogamia, consiste en que Martín Rivas se publicó por primera vez en el periódico La Voz de Chile en mayo de 1862, en un formato de folletín o entrega por capítulos ${ }^{9}$. El periódico, que había entrado en circulación un par de meses atrás, era dirigido por Manuel Antonio Matta, vocero principal del ala más radical del liberalismo. La publicación en este medio de comunicación constituyó una oportunidad para Blest, políticamente un

\footnotetext{
${ }^{8}$ Archivo Nacional, Escrituras públicas de Santiago (Notarios), 1862.

${ }^{9}$ La publicación de Martín Rivas en La Voz de Chile se inició el 7 de mayo de 1862 y finalizó el 18 de julio del mismo año.

El primer ejemplar del periódico circuló el 12 de marzo de ese año.
} 
liberal moderado y todavía un escritor que no alcanzaba la fama, pero también resultó provechosa para ampliar la esfera social de influencia del radicalismo de Matta. El periódico difundió el ideario de esta corriente, la más progresista en ese momento político en Chile, aglutinó a sus simpatizantes y se convirtió en un ícono fundacional para quienes constituyeron el partido radical. En el listado de constituyentes de la asamblea radical de Santiago de 1864, la mayor parte fueron personas relativamente desconocidas de clase media (Gazmuri, 1999, p. 133). Esos doscientos constituyentes formaron el núcleo del público lector de La Voz y de Martín Rivas, pero su alcance social era mayor.

¿Cómo fue percibido el entretejido homogámico-heterogámico de la narración? La Voz siguió el pulso de los lectores, un par de semanas después del inicio de la publicación de Martín Rivas: un día aumentó la frecuencia de publicación de los capítulos ante la demanda del público, en otra ocasión se excusó ante los lectores por cometer la "falta" de suspender un día el folletín, luego solicitó su dispensa por cambiar la página en que era editado, más adelante respondió a "siete lectoras que en su nombre y en el de otras nos piden, por carta de hoy, que publiquemos doble cantidad de la interesantísima novela" y finalmente anunció el final del folletín "para satisfacción de la legítima curiosidad de nuestras lectoras y nuestros lectores" -anteponiendo el género femenino al masculino ${ }^{10}$. Blest Gana, por su parte, relató la reacción del público lector en una carta a su amigo íntimo José Antonio Donoso: "sensación en el público, coro de felicitaciones, artículos lisonjeros, quejas de las mujeres cuando se interrumpe su publicación, cartas de elogios, todo llueve sobre el autor como una lluvia de flores" (Donoso, 1935, p. 21).

Las características sociales de quienes leyeron con ese entusiasmo Martín Rivas, siguiendo una trama donde la homogamia constituía un problema crucial, constituyen un elemento central respecto del tema que nos interesa, según veremos más adelante. El público lector para las novelas y folletines estaba constituido por las capas urbanas letradas (Guerra, 1987; Subercaseaux, 1997, pp. 63-64). Parte de ese público fue presumiblemente el destinatario de la publicación de Martín Rivas en $\mathrm{La}$ Voz y no se trataba sólo de una elite en el poder o del estrato más alto de la sociedad. Cuantitativamente, entre los 110 mil habitantes de 15 años o más en Santiago, 48 mil sabían leer y escribir, lo que representaba una población letrada del $43 \%$, de acuerdo al censo de 1865. Las tasas de analfabetismo eran mayores en los barrios más pobres y alejados de la zona central de la ciudad, según datos del mismo censo, pero tasas intermedias eran observables en sectores donde no residían los más ricos sino con frecuencia personas cuya ocupación y condiciones de vida correspondían a una clase media -como la familia de "medio pelo" en la novela. En el total del país, mayoritariamente rural, la tasa de analfabetismo alcanzaba un $76 \%$ de acuerdo a cifras del censo, de modo que se trataba de un público amplio a nivel urbano pero minoritario a escala nacional. La estrategia de Blest Gana identificaba con claridad ese público lector integrado por la clase media y otros estratos sociales, según expuso al incorporarse como académico en la Universidad de Chile, diagnosticando que junto a "la gente de esmerada educación" se encontraba "una población infinitamente mayor

${ }^{10}$ La Voz de Chile, 24 de mayo, 14 de junio, 27 de junio y 18 de julio de 1862. 
que esa otra, que necesita de la lectura", de modo que las obras dirigidas a satisfacerla "serán sin duda las que más auge obtengan y también más duradera fama" (Blest, 1861 , p. 44). La novela se había convertido en el género literario preeminente de la clase media europea en auge y Blest Gana se orientó hacia un modelo de lector similar (Benítez-Rojo, 1996), poniendo en práctica lo apreciado durante su residencia en Francia.

Con su narración sobre la homogamia, respecto de ese público que según hemos visto era en gran medida de clase media, una estrategia exitosa del autor consistía según Blest Gana, en proporcionar en la ficción "el sabor de la realidad" (Blest, 1861, p. 44). Al finalizar la publicación del folletín, la edición de $L a$ Voz valoró que el novelista era efectivamente un "exacto observador de nuestras costumbres y nuestros caracteres"11. Si la cuestión de la homogamia en la novela constituía una situación considerada verosímil en el imaginario social urbano de clase media, es posible que esto traspasara los límites locales, vinculándose a procesos más generalizables. Así, en Francia en el mismo período, el matrimonio era un factor decisivo de movilidad social para quienes pertenecían a la clase media: se aspiraba a casarse con una persona de un estrato superior al propio, de modo que la homogamia era menos fuerte que en la clase alta y la clase baja (Ariès y Duby, 2001).

Las transgresiones expuestas en la novela a la regla de homogamia o a su forma de aplicación encontraron una exitosa acogida en la clase media, un indicio de la importancia del problema. Pero desde nuestra perspectiva, lo relevante es que la solución planteada por el autor a la historia troncal de Martín y Leonor, permite una respuesta a la pregunta de cómo llega a ocurrir una transgresión. En la novela, la situación inicial consistente en una fuerte desigualdad social entre ambos jóvenes, que impedía cualquier relación afectiva, tuvo como final su confortable matrimonio. ¿Cómo llegó a ocurrir este desenlace inicialmente inviable? ¿Cómo logró el autor que una transgresión a la regla de homogamia fuera interpretada como aceptable por parte del lector? La respuesta fue proporcionada por el propio Blest Gana: los colocó "a una gran distancia social desde el principio", por lo que para llegar a la escena de amor entre ambos decidió situar a los personajes y a la trama en circunstancias grandes o excesivas ${ }^{12}$, retrotrayendo la novela en una década y situándola en el enfrentamiento armado de 1851 contra la designación del Presidente Manuel Montt, de acuerdo a una carta del autor a su amigo José Antonio Donoso (Donoso, 1935, p. 22).

A través de un Martín herido y luego encarcelado, desencadenante de la afectividad de Leonor, Blest Gana proporcionó una solución narrativa a cómo puede ser transgredida la forma establecida de aplicar la regla de homogamia y al mismo tiempo proporcionar evidencia favorable a la mantención de la regla para la clase media -en la historia de Agustín y Adelaida. Para lograrlo, el conflicto armado introdujo elementos de un contexto ajeno al salón elegante o el de clase media en que se desarrollaban normalmente los acontecimientos de la narración. Esos factores externos penetraron en las relaciones cara-a-cara y alteraron lo que los interlocutores consideraban

\footnotetext{
${ }^{11}$ La Voz de Chile, 18 de julio de 1861.

${ }^{12}$ La expresión utilizada por Blest en su carta es "circunstancias muy solemnes", término que en la época incluía el significado "grande o excesivo", de acuerdo al Diccionario de la Lengua Castellana de la Academia Española de 1852.
} 
socialmente establecido y valorado. Si se trató sólo de una solución literaria y puntual o bien ilustra algo más general, constituye un punto que continuaremos revisando.

La transgresión apuntaba a una flexibilización en la aplicación de la regla de homogamia entre quienes controlaban el poder, abriendo oportunidades bajo condiciones como las que reunía Martín, a la naciente clase media de las ciudades. Pero en la práctica, estas nuevas condiciones permitían uniones matrimoniales con la clase alta sólo a una parte de las clases medias descritas cuantitativamente en el anterior Gráfico 1. Se flexibilizaban para el estrato de Servicios integrado por profesionales, directivos y empresarios, mientras continuaba excluida la mayoría de las clases medias, el estrato de Rutinas No-manuales constituido por empleados de oficinas y el de los Independientes, conformado por comerciantes y otros prestadores de servicios, quienes sumaban un $6 \%$ de las ocupaciones. En lo fundamental, desarrollando lo sostenido por Elias (1998), la regla de homogamia que excluía a la mayor parte de la clase media de las alianzas matrimoniales con la clase alta, puede ser interpretada como impuesta por un grupo que utilizó su superioridad de poder para estigmatizar y mantener en una posición inferior a una clase todavía marginal desde un punto de vista cuantitativo y socioeconómico.

Uno de los aspectos más sobresalientes de esa estigmatización consiste en que los propios marginados, incluyendo parte del público lector de Martín Rivas, al aplaudir la novela evidenciaban una adaptación realista a la regla de homogamia, considerada como una condición necesaria para su propio progreso como clase media. La negación afectiva y emocional implícita en la aceptación de esa regla de homogamia por parte de personas que formaban parte de la clase media -siguiendo el ejemplo de Edelmira en la novela-, implicaba tácitamente reconocer su menor valor social y humano. Es posible conjeturar, sin poder verificarlo en la época, que la popular acogida de la novela en la clase media, involucraba en alguna medida una aprobación del bloqueo a sus propias posibilidades de movilidad social ascendente. La fantasía colectiva sobre la regla de homogamia hacía atractiva, gratificante y popular la sumisión a la respetada imagen del grupo que monopolizaba el poder.

\section{De la "Matriz Clásica" del siglo xx a la Transgresión Psicodélica}

El estado oligárquico y el modelo de economía "hacia afuera" entraron en crisis alrededor de 1920, provocando la más profunda transformación política, económica y social desde la independencia. Surgió una "matriz clásica" que perduró durante gran parte del siglo XX, en el marco de la cual el Estado intervino en la economía e impulsó una estrategia de sustitución de importaciones, mientras se estableció un nuevo sistema de representación política a través de partidos políticos, algunos de los cuales ejercieron un rol de intermediación respecto de las demandas de una base social con la que se encontraban articulados (Garretón, 2007).

Formaron parte de esa base social las clases medias, que continuaron expandiéndose entre 1920 y 1970, hasta alcanzar un tamaño significativo a nivel nacional a fines del período, como se aprecia en el Gráfico 2 referido a la composición de las clases sociales en el año 1970. 
Gráfico 2. Clases sociales según ocupación en Chile, 1970

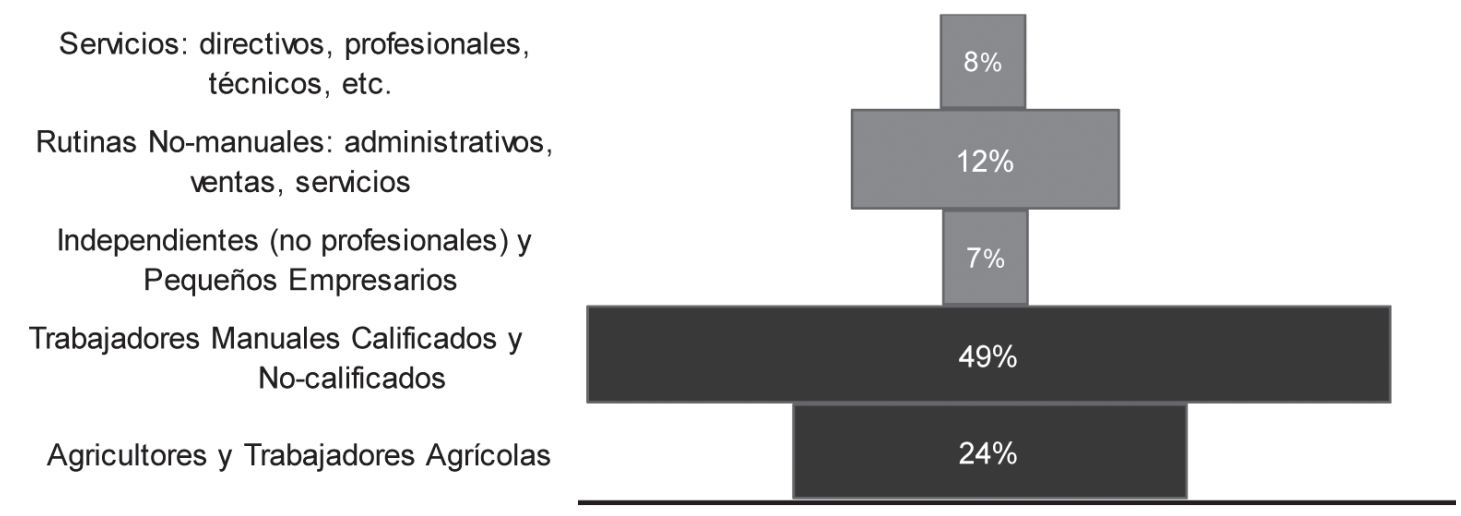

Fuente de los datos: Censo 1970.

Los Trabajadores Manuales Calificados y No-calificados representaron casi la mitad de la ocupación, mientras decayó la participación del empleo agrícola a una cuarta parte de los ocupados, de acuerdo al Gráfico 2. Continuando la tendencia incipiente observada en las ciudades durante el siglo XIX, creció a nivel nacional el estrato de Servicios, integrado por directivos, profesionales y técnicos, entre otros. Sin embargo, este estrato medio-alto fue sobrepasado por la clase de Rutinas Nomanuales conformada por empleados administrativos del sector privado y en menor medida del público, así como por personas contratadas para actividades de ventas y servicios, un conglomerado de nivel medio-bajo que pasó a ser predominante en las clases medias. En su conjunto y a escala nacional, las clases medias crecieron pero eran todavía de un tamaño inferior a las clases de trabajadores manuales.

Desde este punto de vista cuantitativo, había un fundamento para la interpretación de la corriente principal de las ciencias sociales de la época en Chile, que asimiló la clase media a la noción de una clase intermedia y sin existencia propia, capturada en el conflicto entre la burguesía y una numerosa clase obrera. Más recientemente, la corriente de la "historia social" puso de relieve que no hubo una identidad común de clase media, sino múltiples formas en que los integrantes de las clases medias se reconocían y eran reconocidos, como las identidades de los profesionales, los funcionarios públicos y los empleados particulares (Salazar y Pinto, 1999).

En las ciencias sociales y la producción historiográfica se asignó también especial atención a la acción colectiva de las clases de trabajadores manuales, así como de pobladores, estudiantes, campesinos y ocasionalmente de clases medias. Esto incluyó formas de transgresión del orden establecido consistentes en acciones colectivas de carácter disruptivo en espacios públicos a través de un repertorio como las reuniones o asambleas masivas, las manifestaciones o protestas públicas, las huelgas, tomas u ocupaciones, los actos performáticos y simbólicos, el uso de la violencia frente a bienes o el enfrentamiento físico con la policía o contrincantes, entre otros actos.

Además de esas acciones disruptivas, ante todo expresivas y en ese sentido relativamente irreflexivas, siguiendo lo planteado al inicio de este trabajo, otras 
formas de transgresión situadas en espacios predominantemente privados, también pueden haber ejercido variados efectos durante el período. A modo de ilustración, reformas en las reglas para celebrar actos como los religiosos y que han pasado a ser considerados parte de la vida privada, cambios en los métodos pedagógicos, transformaciones en el modelo de familia y otras alteraciones de prácticas sociales establecidas que condicionan a las personas en la vida social. En este segundo tipo de acciones se encuentran las transgresiones de las normas relativas a las uniones de pareja, nuestro objeto de estudio.

A principios del siglo XX, la desintegración de la estructura de poder oligárquico y del sistema económico orientado a la exportación, estuvo acompañado de una declinación de las redes familiares que habían controlado la sociedad, según el trabajo de Balmori y Oppenheimer (Balmori \& Oppenheimer, 1979, Balmori, Voss y Wortman, 1990). De acuerdo a estos autores, los recursos económicos -de capital, tecnológicos y humanos- sobrepasaron la escala y el nivel de operaciones en que resultaban eficientes las redes de confianza en que se movía una familia. En el plano político, las estructuras gubernamentales y partidarias excedieron la capacidad de control de las familias que contaban con una posición superior de poder. En la clase alta se produjo una adaptación a este nuevo contexto, incluyendo una flexibilización a través de estrategias de matrimonio más exogámicas, lo que como veremos involucró a la clase media.

Desde principios del siglo XX, profesionales, intelectuales, pequeños empresarios, en general personas con un nivel educacional más elevado que otros estratos, instauraron un ideal mesocrático basado en la educación y el esfuerzo propio. Desarrollaron una identidad más valorada socialmente que durante la dominación oligárquica del siglo XIX, asumieron una representación de la clase media y ejercieron una cuota importante del poder político (De León, 1964, Salazar y Pinto, 1999). Muchos de los integrantes de este estrato medio-alto desempeñaban ocupaciones como las de médico, abogado o ingeniero, de mayor prestigio social que los empleados en actividades rutinarias (Carter \& Sepúlveda, 1964; González, 2011).

Su posición relativamente favorable, agregada a las estrategias de matrimonio más heterogámicas de la clase superior, posiblemente favoreció alianzas matrimoniales exogámicas y la movilidad ascendente del estrato de Servicios de las clases medias. Según el historiador conservador Jaime Eyzaguirre (1978, p. 171), más allá de su discurso crítico frente a la clase alta, "el chileno de la capa media (...) vivía en la esperanza de lograr con sus miembros un vínculo de sangre o de amistad". Confirmando lo señalado, de acuerdo al testimonio del historiador Alfredo JocelynHolt (Contardo, 2008, p. 212), en la capa superior de las clases medias en las primeras décadas del siglo $\mathrm{XX}$, se hizo posible que un hombre entablara matrimonio con una mujer de clase alta y experimentara un ascenso social, aunque sin ser plenamente aceptado por quienes integraban esta última clase.

El conglomerado más numeroso pero socialmente menos valorado entre los profesionales de clase media, compuesto por profesores y profesiones como la 
de matrona y dentista, permaneció ajeno a esa pauta de alianzas matrimoniales. Experimentaron una movilidad intergeneracional de tipo horizontal al interior de la clase media, pues su origen provenía de los estratos de empleados, comerciantes y prestadores de servicios, que en su conjunto habían sido el componente mayoritario de esta clase en el siglo XIX (González, 2011).

El estrato cuantitativamente más amplio de las clases medias pasó a estar integrado por los empleados públicos (Candina, 2009) y principalmente por los empleados de oficina en el sector privado, a lo largo del período de la "matriz clásica" del siglo XX. Fueron considerados el prototipo de una clase media-baja con un escaso horizonte de ascenso social (Salazar y Pinto, 1999) y en el caso de los funcionarios públicos articularon una demanda de justicia social en conjunto con los trabajadores manuales (Candina, 2009). Aparentemente desarrollaron procesos de movilidad horizontal al interior de esta clase de Rutinas No-manuales y predominaron las uniones matrimoniales homogámicas dentro de este mismo estrato, de manera análoga a los profesionales de nivel medio-bajo de la clase de Servicios.

La homogamia fue percibida como un problema social durante la "matriz clásica" del siglo XX en Chile. Así lo atestigua la película Palomita Blanca del cineasta Raúl Ruiz, basada en la novela de Enrique Lafourcade, además de diversas otras obras literarias ${ }^{13}$. La insípida novela homónima había constituido un gran éxito editorial en 1971, debido al interés del público más que a su valor literario (Subercaseaux, 2010). Buscando proyectar la popularidad de la novela, la filmación generó fuertes expectativas por su producción de gran escala en relación a lo habitual en esos años, el multitudinario casting para los papeles protagónicos y el prestigio ya adquirido por el director ${ }^{14}$.

Transmutada la historia al lenguaje cinematográfico del cineasta, el filme de Ruiz resulta de interés para nuestro análisis, debido a que expone una transgresión a la regla de homogamia y en una forma particularmente reveladora del mecanismo mediante el cual se le vulnera. En una entrevista poco antes del golpe militar, en la misma época en que fue filmada la película, Ruiz declaró que el cine le ayudaba a revelar elementos "normalmente elusivos" de la realidad social (Chanan, 1976), como a nuestro juicio lo hizo respecto de la homogamia.

La historia fue contada por Ruiz en forma no omnisciente y el espectador-receptor de la película habría podido ver más que lo que veía María, la ingenua protagonista (De los Ríos, 2010). La trama central es la historia de amor de ella, hija de un obrero, con un joven de familia adinerada, a quien conoció en un recital hippie, el festival de Piedra Roja, poco después de la elección de Salvador Allende como Presidente. María pertenecía a una familia de obreros pero era estudiante en un liceo en 1970. De acuerdo a estadísticas educacionales oficiales, la cobertura de la enseñanza media se

\footnotetext{
${ }^{13}$ La homogamia en el establecimiento de vínculos de pareja fue también tematizada por algunos de los autores y textos más destacados de la literatura narrativa nacional durante la "matriz clásica" del siglo XX chileno: Orrego Luco en Casa Grande, Joaquín Edwards Bello en La chica del Crillón, Vicente Grez en El ideal de una esposa, Augusto d’Halmar en Juana Lucero, María Luisa Bombal en La última niebla y Guillermo Blanco en Gracia y el forastero.

${ }^{14}$ La película no se alcanzó a estrenar, debido al golpe militar.
} 
había elevado a un $49 \%$ ese año, lo cual abriría una posibilidad de movilidad social para jóvenes como la protagonista.

El entretejido cinematográfico de Ruiz aportó dos claves centrales. Piedra Roja abrió una nueva oportunidad a los jóvenes hippies de clase baja, quienes querían ser como los de clase media: la contra-cultura del hippismo, expresada en el festival, les proporcionó los marcadores sociales necesarios para asumir una nueva identidad y transgredir los límites de clase (Barr-Melej, 2009), permitiendo incluso, en el caso de María, establecer un vínculo amoroso con un joven de clase alta. Por otro lado, un profesor del liceo de la protagonista, en una escena célebre del filme, inexistente en la novela de Lafourcade, criticó ante las alumnas a sus colegas tradicionales y conservadoras, proponiéndoles una forma alternativa de valorar la vida.

Desde nuestra perspectiva de análisis, lo interesante consiste en cómo ocurrió la transgresión del principio de homogamia visibilizado por Ruiz. El hippismo, una tendencia cultural transnacional, valores críticos introducidos contra y a través del sistema educacional, así como el propio sonido de la música en el festival -y del grupo Los Jaivas en el filme-, es decir, un contexto externo a los personajes, intervino para hacer plausible la transgresión de la regla de homogamia.

\section{El período post-dictadura: clausura homogámica en la clase media-alta}

A partir de inicios de la década de 1970, en América Latina y en Chile, la matriz sociopolítica de gran parte del siglo XX fue reemplazada por una autonomía de la economía respecto de la política, dificultando el surgimiento de categorías sociales -como la clase obrera en el pasado histórico- capaces de aglutinar a grandes conglomerados de la población frente a las estructuras predominantes (Garretón, 2007). Como contrapartida a la liberalización y globalización de la economía, se incrementó el empleo en las actividades del sector terciario, generándose una nueva composición de las clases sociales desde el punto de vista ocupacional (León y Martínez, 2001). A esto se agregó el efecto de la ampliación de la educación, lo que facilitó procesos de movilidad social ascendente hacia empleos de clase media (Torche y Wormald, 2004). Todo lo cual se ha traducido en una composición del conjunto de las clases sociales sin precedentes respecto de los períodos históricos previos, como se aprecia en el Gráfico 3. 
Gráfico 3. Clases sociales según ocupación en Chile, 2009

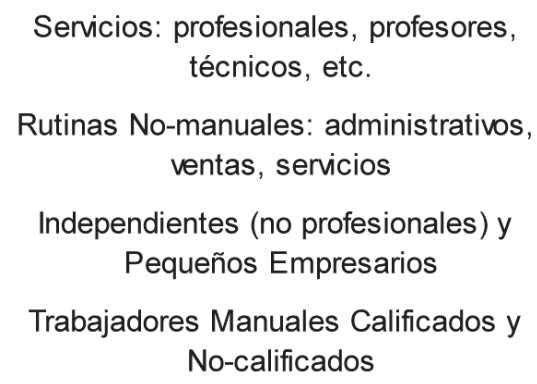

Fuente de los datos: Encuesta CASEN 2009.

Nota: Datos 2009 corresponden a ocupados entre 25 y 65 años de edad. Se excluye a grandes empresarios.

La clase de Servicios ha desplazado la relevancia porcentual que antes tenía la clase de Rutinas No-Manuales, al interior de las clases medias, alcanzando un $21 \%$ y un 18\% respectivamente en la ocupación total, según el Gráfico 3. Esta clase de Servicios se encuentra conformada predominantemente por profesionales y técnicos de nivel alto contratados tanto en el sector privado como público, ejecutivos de empresas y funcionarios con cargos directivos en el Estado. En un escalón más abajo, está integrada también en una elevada proporción por profesores, profesionales de servicios administrativos, técnicos con formación superior, profesionales de nivel medio de la salud y profesionales de la comunicación. En su conjunto, las clases medias han pasado de tener un peso cuantitativamente menor a ser predominantes en la ocupación, transformando la configuración de la estructura de clases.

En la etapa post-dictadura y ya establecido el modelo neoliberal, nos parece de interés seleccionar la novela Nosotras que nos queremos tanto de Marcela Serrano para una aproximación cualitativa a nuestro objeto de estudio. En el libro, un éxito de ventas en la década de 1990, las protagonistas fueron cuatro mujeres integrantes de la clase media profesional, aunque provenientes de diversos orígenes sociales. La novela buscaba encontrar en ellas una identidad compartida y un proyecto político de género:

"cuando yo publiqué mi primera novela, Nosotras que nos queremos tanto -señaló la autora en una entrevista académica-, tuve una avalancha de preguntas acerca del por qué de estas historias de mujeres. Y yo dije claramente que estaba segura de que todas nosotras, de alguna u otra forma, teníamos la misma historia que contar; y por eso creo que mis libros han tocado tantos corazones de esas mujeres. Esta perturbación ha sido mi tema, siempre con trasfondo político (...)" (García-Corrales, 1997, p. 232).

Parte del éxito editorial del libro, en especial en un público lector femenino, obedecería a que la autora aparecía mimetizada con las emociones de sus personajes, aportando un sello de familiaridad a conductas que, estableciendo una distancia, podrían haber 
sido cuestionadas por el público, según observa Bianchi (2001). Una familiaridad manifestada, por ejemplo, en la narración sobre María, la protagonista principal, cuyos amores prohibidos adolescentes con jóvenes de clase baja fueron pronto reemplazados por sus verdaderas relaciones con el otro sexo. La narración se compone de múltiples historias donde se suceden relaciones afectivas y de pareja con hombres del mismo mundo de clase media-alta, integrado por profesionales, ejecutivos, intelectuales y políticos. Desde nuestra perspectiva analítica, se trata de una historia definida en general por una homogamia en la clase media-alta ${ }^{15}$.

Esa indiscutida homogamia se aviene sin problema con las historias de vida asociadas a una militancia de izquierda de las mujeres protagonistas de la novela, lo que incluso tuvo como consecuencia el exilio de María durante el período dictatorial. De acuerdo a las distinciones expuestas al inicio de este artículo, sus posturas críticas en el texto narrativo deslegitimaban las reglas de justificación abiertamente instituidas acerca de desigualdades sociales como las de género, pero al menos respecto de la homogamia, no transgredían principios relativamente inconscientes que les condicionaban subjetivamente a adaptarse a normas establecidas. En el texto analizado, la ausencia de transgresión expresada en la "naturalización" de la homogamia, se encuentra desbalanceada respecto del peso asignado a historias de vida marcadas por el rechazo al sistema político y social, que en gran medida define el centro de gravedad de la narración.

La revisión de la novela por parte de Bianchi (2001), destacando la ausencia de problematicidad en la narración, se encuentra entrelazada con lo que ya hemos sostenido acerca del modo como ocurre o no ocurre la transgresión. Sostiene que es una representación distanciadora la que permite reconocer el objeto, mostrándolo como algo externo y ajeno, lo que no ocurre en la novela de Serrano. En contraste, un distanciamiento entre los actores y el contexto que los enmarca, quitando a las reglas su aspecto de familiaridad, normalidad y naturalidad, puede ser desencadenado por acontecimientos externos a los actores involucrados, según observamos en Martín Rivas y Palomita Blanca. Comparativamente, cuando esto no ocurre y los principios de homogamia son asumidos como naturales, según examinamos en el escenario contrafactual de Nosotras que nos queremos tanto, permanece inalterada la validez social de prácticas como las homogámicas. Este acatamiento "naturalizado" de las reglas homogámicas ocurrió en una novela que formó parte de una corriente -generacional, en alguna medida- en la literatura chilena, donde los personajes permanecían atrapados en espacios sociales uniformizados y encerrados en sí mismos, sin salidas ni sentidos de superación, condenados a una especie de orfandad, de acuerdo a Cánovas (1997), contextos en los que continuando nuestro análisis, no habían condiciones para los mecanismos de transgresión.

\section{Homogamia en las clases medias y evidencia empírica actual}

La uniformidad homogámica en la clase media-alta que hemos apreciado a partir de Nosotras que nos queremos tanto, encuentra un correlato en datos empíricos

\footnotetext{
${ }^{15}$ La aceptación de las reglas de homogamia como algo "natural" estuvo presente también en novelas del período anterior, por ejemplo, en Casa Grande de Orrego Luco.
} 
cuantitativos para el mismo período y de los que no disponíamos para las épocas anteriores, como podremos analizar a continuación. Una uniformidad similar aunque con otro signo se puede observar en los restantes estratos de clase media y en otras clases sociales, según examinaremos.

Los estudios de que se dispone para Chile y América Latina (Torche, 2007; Esteve \& McCaa, 2007) ofrecen suficiente evidencia empírica respecto de una homogamia educacional en la conformación de las parejas. El aspecto que falta analizar cuantitativamente consiste en establecer si hay un vínculo entre esa homogamia educacional y las clases sociales. Para aproximarnos a esto, realizamos una descripción cuantitativa de la asociación absoluta entre las clases sociales según la ocupación de los cónyuges hombres y los niveles educacionales de las cónyuges. En la tabla siguiente, analizamos a las parejas existentes en todos los núcleos familiares del país, según la clase social de los hombres de 25 a 39 años de edad y el nivel educacional de la mujer en el año 2009, utilizando datos de la principal encuesta de hogares del país.

Tabla

Parejas de acuerdo a la clase social según ocupación de los hombres de 25 a 39 años de edad y nivel educacional de cónyuge mujer, Chile 2009

\begin{tabular}{|c|c|c|c|c|c|c|}
\hline \multirow[b]{2}{*}{ Clase social hom bre } & \multicolumn{4}{|c|}{ Educación cónyuge mujer } & \multirow{2}{*}{\multicolumn{2}{|c|}{ Total }} \\
\hline & $\begin{array}{l}\text { educación } \\
\text { formal o } \\
\text { Básica } \\
\text { incompleta }\end{array}$ & $\begin{array}{c}\text { Básica } \\
\text { complets o } \\
\text { Media } \\
\text { incomplets }\end{array}$ & $\begin{array}{c}\text { Media } \\
\text { complets o } \\
\text { superior } \\
\text { incompleta }\end{array}$ & $\begin{array}{c}\text { Universitaria o } \\
\text { Técnica } \\
\text { completa }\end{array}$ & & \\
\hline Servicios Alta (profesionales, etc.) & $0 \%$ & $1 \%$ & $28 \%$ & $73 \%$ & $100 \%$ & 57.753 \\
\hline Servicios Baja (profesores, técnicos, etc.) & $1 \%$ & $6 \%$ & $43 \%$ & $50 \%$ & $100 \%$ & 86.710 \\
\hline Rutinas No-manuales Alta (administrativos, etc.) & $4 \%$ & $15 \%$ & $58 \%$ & $25 \%$ & $100 \%$ & 48.178 \\
\hline Rutinas No-manuales Baja (ventas y servicios) & $3 \%$ & $12 \%$ & $67 \%$ & $18 \%$ & $100 \%$ & 41.193 \\
\hline Pequeños Empresarios & $2 \%$ & $20 \%$ & $48 \%$ & $24 \%$ & $100 \%$ & 6.102 \\
\hline Independientes & $7 \%$ & $20 \%$ & $54 \%$ & $13 \%$ & $100 \%$ & 62.736 \\
\hline Manuales Calificados & $7 \%$ & $20 \%$ & $57 \%$ & $10 \%$ & $100 \%$ & 141.521 \\
\hline Manuales No-calificados & $11 \%$ & $32 \%$ & $50 \%$ & $8 \%$ & $100 \%$ & 164.182 \\
\hline Trabajadores Agricolas & $25 \%$ & $38 \%$ & $38 \%$ & $2 \%$ & $100 \%$ & 60.240 \\
\hline Agricultores & $24 \%$ & $42 \%$ & $29 \%$ & $5 \%$ & $100 \%$ & 19.869 \\
\hline Total & $8 \%$ & $23 \%$ & $48 \%$ & $21 \%$ & $100 \%$ & 688.484 \\
\hline
\end{tabular}

Nota: Excluye a patrones o empleadores en clase de Servicios Alta.

Fuente: Elaboración propia según datos de Núcleos Familiares en Encuesta CASEN 2009.

Considerando las parejas que residen en los hogares, la tabla anterior distingue la clase social a la que pertenece el hombre que comparte un núcleo familiar con una cónyuge. Las clases sociales son definidas según la ocupación desempeñada, de acuerdo a una matriz estandarizada, la más utilizada a nivel internacional, la escala EGP de Erikson y Goldthorpe (1993) según lo indicado anteriormente. Se considera sólo a las nuevas cohortes de hombres, lo que tentativamente abarca a quienes nacieron a partir de 1970, por lo que se incorporaron a la actividad laboral una vez reestructurada la economía chilena en función de los principios neoliberales. Dejamos de lado a los menores de 25 años debido a su situación menos estable e incluimos solamente a los ocupados hasta 39 años de edad en la encuesta del año 2009, es decir, 
a las nuevas cohortes de quienes están en la etapa del ciclo vital en que habitualmente se establecen vínculos matrimoniales o uniones de pareja. Respecto de las mujeres cuyo cónyuge es uno de estos hombres, se distingue su nivel educacional, agregado en grandes categorías para facilitar la revisión de los resultados. Se excluye de la tabla a los patrones o empleadores en el estrato más alto, respecto de quienes se requeriría un método específico de recolección de datos.

La tabla permite apreciar los resultados para las 688 mil parejas chilenas en las cuales el hombre pertenece a las nuevas cohortes; en estas parejas el $91 \%$ de las mujeres pertenece a las mismas cohortes. En primer lugar, la tabla nos permite abordar cuantitativamente la pregunta de en qué medida se observa una homogamia o bien, por el contrario, no existe relación entre la clase social del hombre y el nivel educacional de la mujer y por tanto, la educación no es una variable tomada en cuenta en la selección de la pareja. Como indicador de homogamia, podemos considerar ante todo si en cada clase social hay niveles educacionales donde se concentre la distribución de parejas.

En la clase de Servicios Alta integrada en su mayor parte por profesionales y técnicos de nivel alto como médicos, ingenieros y abogados, el criterio de selección de cónyuges es marcadamente homogéneo, con parejas donde en un $73 \%$ de los casos la mujer cuenta con educación superior completa. Así, en este estrato de clase media-alta predominan las uniones homógamas, es decir, las cónyuges tienen un similar nivel educacional, en general, graduadas universitarias. Esto es menos acentuado en la clase de Servicios Baja, integrada principalmente por profesores, técnicos, profesionales de servicios administrativos, técnicos con formación superior, profesionales de nivel medio de la salud y profesionales de la comunicación, entre quienes la proporción de cónyuges graduadas universitarias desciende a un $50 \%$.

En el resto de las clases medias, siguiendo el criterio convencional que las define como integradas por estratos de trabajadores no manuales, la situación es bastante diferente, pues en su mayoría son parejas donde la mujer cuenta con educación media completa, en una proporción variable según el estrato. Sólo una minoría de ellas ha egresado de la universidad, un $25 \%$ en el estrato de Rutinas No-manuales Alta compuesto en elevada frecuencia por empleados administrativos y este porcentaje es aún menor en los restantes estratos de clase media. La clase de Rutinas Nomanuales Baja, integrada principalmente por vendedores, cajeros y camareros, puede considerarse el prototipo de una clase media-baja, en la cual un $67 \%$ de las parejas está integrada por una cónyuge que ha llegado hasta la educación media completa. Incluso en la clase de Pequeños Empresarios que cuentan con empleados y entre los Independientes que en su mayor parte son trabajadores no-manuales, la proporción con educación media también es mayoritaria.

La diferencia con la clase Servicios Alta se agudiza en las clases de trabajadores Manuales Calificados y No-calificados, si se considera que además de una elevada proporción de cónyuges con educación media, el porcentaje que cuenta con educación básica supera con creces a quienes han alcanzado una educación universitaria. 
Una situación extrema se aprecia en las clases sociales del sector agrícola, donde predominan las cónyuges que apenas han alcanzado la educación básica o incluso carecen de educación formal, una característica opuesta a la observada en la clase de Servicios Alta. Considerando el peso relativo de las diversas clases sociales y niveles educacionales en el conjunto de la población, los trabajadores manuales Calificados y No-calificados con cónyuges mujeres egresadas de educación media, constituyen el grupo proporcionalmente más numeroso en la suma total de las nuevas cohortes en el país, un $11 \%$ y un $12 \%$ del total respectivamente. De este modo, la educación media de las mujeres constituye un marcador importante, nivelando "hacia abajo" a la mayor parte de las clases medias.

Además de la concentración de las uniones de pareja de cada clase social en asociación a un nivel educacional, la homogamia puede evaluarse también en función de la simetría de la distribución de la educación, es decir, habría menor homogamia si esta segunda variable se distribuyera de modo uniforme, más allá del nivel en que se aprecia una mayor proporción. Por ejemplo, en la clase de Rutinas No-manuales Baja, el estrato compuesto por vendedores y otras personas que prestan servicios, no se observa una misma frecuencia porcentual en los niveles educacionales inferiores a Educación Media, sino que éstos decrecen paulatinamente, de modo que las variables clase y educación se encuentran asociadas asimétricamente. Como apreciación general, esta gradualidad asimétrica es observable en todas las clases sociales, lo que refuerza la tendencia mayoritaria a formar uniones conyugales de un modo homogámico.

La distribución según clases sociales de los hombres en la tabla, muestra porcentajes más diferenciados que cuando se comparan niveles educacionales de ambos cónyuges (Torche, 2007), particularmente en los estratos medios, lo que podría indicar una mayor incidencia de las clases sociales que la educación en la explicación de la homogamia, confirmando lo sugerido por Esteve \& McCaa (2007, p. 79).

Un aspecto importante y complementario a nuestra revisión previa, consiste en que con la marcada homogamia en la clase de Servicios Alta, el predominio de cónyuges con educación superior se encuentra correlacionado en la sociedad chilena con un retorno económico más elevado y una mayor valoración en términos de prestigio social. Dada esta clausura homogámica, no es de extrañar la normalidad a-problematizadora con que se asume subjetivamente, lo cual valida la relevancia de la autoconciencia de los actores sobre sus prácticas en la conformación de parejas, expuesta en la novela Nosotras que nos queremos tanto.

La homogamia, sin embargo, no es exclusiva de ese estrato donde las mujeres son predominantemente graduadas universitarias, pues en las restantes clases medias hay una elevada proporción de cónyuges con educación media, lo que constituye un criterio uniformizado en la selección de pareja, de acuerdo a la tabla. De manera general, en las parejas chilenas donde el hombre pertenece a las clases medias, una elevada proporción involucra cónyuges mujeres de un nivel educacional específico según cuál sea el estrato de pertenencia del hombre. En este sentido, los criterios homogámicos acerca de cómo debe ser establecida la unión de pareja o el matrimonio, 
son compartidos por la mayoría de las personas pertenecientes a la clase media chilena.

La clausura homogámica que se aprecia en la tabla, más intensa en la clase media-alta pero también presente en el resto de las clases medias, conlleva efectos relevantes. En la medida que las personas de un estrato medio se unen con quienes tienen un nivel educacional específico, de manera diferente a como ocurre en otras clases según hemos apreciado en la tabla, este proceso refuerza la desigualdad experimentada por la pareja en comparación a otros y la reproduce en la generación siguiente, pues las ventajas o desventajas en el acceso a recursos se transmiten de modo inmodificado. En términos de ingresos del trabajo, contar con educación media marca una diferencia significativa, pero ese nivel de ingresos es bastante inferior al resultante de tener educación universitaria.

El análisis de la tabla que hemos realizado hasta aquí se refiere a la homogamia, pero una segunda pregunta de la mayor relevancia para nuestro estudio consiste en establecer en qué medida los datos muestran en algún grado la presencia de heterogamia.

La heterogamia puede ser entendida desde el punto de vista de los datos utilizados, como la situación de parejas donde el hombre de una clase social tiene como cónyuge una mujer cuyo nivel educacional se encuentra a una marcada distancia respecto del predominante en esa clase. Mientras esto sea más dispar, sería más improbable que exista una unión y si la hubiera consistiría en un vínculo heterogámico. Como indicador de esta distancia elevada, podemos considerar en cada clase los niveles educacionales de las cónyuges que se alejan en más de un nivel respecto del predominante, según la tabla. Como ilustración, en la clase de Rutinas No-manuales Baja de los empleados en ventas, servicios administrativos y otros, un pequeño porcentaje de las cónyuges carece de Educación Básica completa, lo que dista más de un nivel respecto de contar con Educación Media que es lo predominante en esta clase -siendo la Educación Básica completa el nivel inferior que le sigue. De modo análogo, se aprecia una distancia elevada en otros estratos medios y en el resto de las clases sociales, aunque en un pequeño porcentaje de las parejas. Esto confirma que la heterogamia es cuantitativamente menor en la actualidad, pero no inexistente.

Acerca de esa escasa proporción cuantitativa de parejas conyugales heterógamas, queda abierta la interrogante de cuál es su autopercepción de esa situación y cómo es percibida por otras personas. Pero se trata de una heterogamia que transgrede prácticas predominantes respecto de las desigualdades sociales. Es decir, consiste una forma de transgresión aunque los juicios subjetivos no se manifiesten públicamente ni haya un elevado grado de reflexividad social sobre esa heterogamia.

Desde nuestra perspectiva de análisis, de modo más general, los datos analizados confirman que la homogamia, presente en el conjunto de las clases medias y en general en todas las clases, es parte de los procesos que reproducen las desigualdades sociales. Sin embargo, la heterogamia está presente en una pequeña proporción de 
las clases medias. Esto nos conduce nuevamente a una dimensión crucial para la comprensión de este importante fenómeno, el mecanismo o proceso sea de aceptación o de transgresión de la homogamia, sobre lo que concluiremos enseguida.

\section{Homogamia y clases medias en perspectiva histórica}

De acuerdo a lo expuesto, la homogamia ha estado y continúa estando en el centro de las desigualdades sociales en Chile a lo largo de dos siglos. Obras clásicas de la literatura narrativa y el cine chileno, Martín Rivas y Palomita Blanca respectivamente, nos permiten observar intentos ficticios de transgredir las reglas de homogamia propiamente tales. En ambas, esos intentos fracasaron, ilustrando la fortaleza de reglas de homogamia que aparecían como naturales, por sobre la negación afectiva y emocional implícita en la aceptación de esa regla por parte de las personas que formaban parte de la clase media. Las prácticas homogámicas en las que se ha visto involucrada la clase media han estado en el núcleo de las desigualdades sociales sin ser necesariamente su causa, pero constituyendo un mecanismo que las ha reproducido.

Lo ocurrido podría no ser muy diferente a lo acaecido en sociedades similares, pero una perspectiva histórica ha dejado al descubierto las formas particulares de la homogamia y los intentos de transgresión de ese tipo de práctica social en las clases medias chilenas. Además, ha proporcionado evidencias que posiblemente son más reveladoras que las de un análisis reducido a un momento en el tiempo.

La homogamia estuvo marcada en el pasado histórico por el peso de la familia y la religión en la constitución de las parejas de clase alta. Las personas integrantes de la clase media en el siglo XIX, todavía pequeña y subordinada a quienes controlaban el poder, pertenecían predominantemente a un estrato bajo de comerciantes y empleados en las ciudades, quienes se adaptaron a sus condiciones sociales estableciendo uniones conyugales entre sí. Pero cuando esas influencias y condiciones se debilitaron, los datos expuestos muestran que ha perdurado la fuerza objetiva de normas homogámicas que refuerzan las desigualdades sociales.

Hacia fines del siglo XIX, los cambios más visibles consistieron en una flexibilización adaptativa de la aplicación de la regla de homogamia en la clase alta, bajo ciertas condiciones como contar con un capital cultural para acceder a conformar parejas heterogámicas. El estrato medio-alto de la clase media integrado por profesionales, resultó favorecido por las estrategias de matrimonio más flexibles de la clase alta y accedió a la posibilidad de uniones socialmente heterogámicas. Pero al finalizar el siglo XX, la tendencia más frecuente en este estrato medio-alto evolucionó hacia una clausura homogámica en torno al principio de contar con educación universitaria, un límite definitorio respecto de otros estratos medios. Actualmente, este rasgo también es compartido, aunque en menor grado, por la clase de Servicios Baja, integrada por profesores, técnicos y otros.

En el estrato mayoritario de las clases medias durante el siglo $\mathrm{XX}$, compuesto por empleados, predominaron las uniones homogámicas al interior de esta misma 
categoría social. En la actualidad, las cónyuges con Educación Media representan un rasgo definitorio en las clases de Rutinas No-manuales, en mayor proporción que las clases de trabajadores manuales. Estas uniones homogámicas donde la mujer sólo cuenta con Educación Media son menos ventajosas económicamente en comparación a lo que ocurre en los estratos de Servicios profesionales. Pero este estrato de Rutinas No-manuales ya no es el mayoritario al interior de las clases medias, como había ocurrido en las épocas anteriores.

En síntesis, reglas homogámicas se establecieron no sólo en la clase alta, sino también dentro de las clases medias, de un modo diferenciado entre un estrato y otro. Mientras en el pasado histórico la homogamia de la clase alta definía orientaciones claves de la sociedad, en la actualidad, cuando las clases medias dejaron de ser minoritarias y bordean la mitad de la población, las reglas homogámicas continúan presentes. Un nivel educacional específico constituye actualmente un marcador relevante en la conformación de las parejas de cada estrato medio y de las restantes clases sociales, lo que no se intenta transgredir de un modo generalizado o sistemático.

\section{Transgresión de la homogamia}

Concluyendo, hemos expuesto un giro en el comportamiento de las clases medias respecto de las uniones de pareja. Mientras en el pasado más lejano la búsqueda de transgredir la homogamia constituía un principio motor del estrato superior de las clases medias, en la actualidad predomina en éste un enclaustramiento y una autocomplacencia en la conformación de las uniones. Ese comportamiento transgresor se extendía a otros estratos de clase media, incluso hasta períodos cercanos, lo que en el presente ha sido reemplazado por un encierro en los límites de cada estrato, aceptando como naturales las distinciones basadas en la educación formal. La naturalización de los límites impuestos por la educación a la conformación de parejas, se constituye así en un potente factor de aceptación del sistema de estratificación.

A pesar de la perdurabilidad de la homogamia, en ciertos períodos históricos ha sido objeto de transgresión por parte de las clases medias, aunque posiblemente de un modo menos sistemático o generalizado que las formas de transgresión expresadas por manifestaciones masivas, las huelgas y otros tipos de acción colectiva de carácter disruptivo en espacios públicos, que a lo largo del tiempo también se han situado en un plano más fáctico o de hecho que en un ámbito de afirmaciones o fundamentaciones razonadas de juicios discursivos. Las transgresiones a la homogamia que hemos revisado en productos culturales y en datos cuantitativos actuales, evidencian un retiro del consentimiento a desigualdades sociales establecidas, de un modo práctico o experiencial, aunque requeriría investigarse el grado en que esto es percibido subjetivamente como un rechazo. Hemos examinado transgresiones a la homogamia que consciente o inconscientemente han apuntado a la distribución de recursos mediante las uniones de pareja, a través de la alteración de vínculos conyugales relacionados con posiciones sociales o de poder político y niveles de educación.

Extendiendo la distinción formulada en la literatura teórica, entre la crítica a cómo deben ser las cosas y a cómo son en un ámbito particular, a lo largo de este artículo pudimos 
analizar dos modalidades en la transgresión de las prácticas sociales, en particular de la homogamia, las cuestionadoras de las reglas en sí mismas y las relativas a formas de aplicación de esas normas.

La transgresión en las clases medias, en un momento $\mathrm{u}$ otro, se ha referido principalmente a lo que son efectivamente los modos más adecuados de aplicar la regla de homogamia a las uniones de pareja o matrimonio y lo crucial no ha radicado en lo que debe ser esa regla. A través de la aceptación de lo que debe ser, los individuos se han "apropiado" de la regla homogámica y posiblemente, con esto han encontrado en su propia experiencia personal y de pareja, pruebas de la validez de otras desigualdades sociales. Es decir, presumiblemente, a través de los vínculos de pareja, no sólo se han reproducido desigualdades socioeconómicas, sino que además se ha proporcionado en los hechos evidencia de un consentimiento acerca de la distribución desigual de los recursos en la sociedad, contribuyendo a que los individuos se convenzan unos a otros de que esto último es lo real o natural.

Aún a pesar de las diferencias derivadas de las particularidades de cada uno de los períodos que hemos analizado, las transgresiones a la homogamia se han desarrollado de acuerdo a procesos que históricamente han presentado ciertas similitudes o al menos han seguido una pauta que hipotéticamente podría proyectarse a contextos históricos diversos.

En primer lugar, la comprensión de la transgresión a una práctica definida como la homogamia, requiere focalizar la atención fuera de las prácticas sociales habituales, observando otros niveles igualmente importantes de la vida social y que generan efectos en reglas como las homogámicas. En su origen, la transgresión puede basarse en una situación contextual que produce una anomalía en las relaciones cara a cara, como una coyuntura de crisis político-social o cultural, lo que quizás podría extenderse a los efectos de crisis económicas o internacionales.

Situaciones coyunturales de crisis político-social pueden alterar la normalidad con que se desarrollan prácticas habituales de homogamia, tal cual ocurrió como efecto del conflicto armado de 1851 en la novela de Blest Gana. De este modo, las normas homogámicas que regulan personales vínculos de pareja, pueden ser afectadas por cambios ocurridos fuera de la interacción cara a cara habitual, situados en la dimensión más amplia de los escenarios o locaciones donde ocurren las interacciones y funcionan las instituciones.

En segundo lugar, la transgresión también puede ser inducida por situaciones de cambio cultural o valórico, es decir, la aparición de un contexto ajeno a la tradición en el campo cultural, eventualmente de carácter transnacional, como en el caso del movimiento contracultural hippie y el célebre discurso del profesor, en la película Palomita Blanca. Las propios productos culturales, como las obras de ficción literaria o cinematográfica analizadas en este artículo, en la relación dialógica con su público destinatario, pueden generar una distancia capaz dejar expuesta una a-problematización, induciendo una mayor reflexividad y una deslegitimación de 
prácticas consideradas naturales.

Una crisis o un cambio cultural muestra la viabilidad o incluso la amenaza de un contexto diferente, desequilibrando formas de interacción a nivel "micro". En contraste, la ausencia de un escenario alternativo que haga plausible una mutación de reglas que uniformizan prácticas como las homogámicas, mantiene y revalida las relaciones cara a cara encerradas en lo establecido, según se pudo apreciar en el caso contrafactual de la novela Nosotras que nos queremos tanto.

De este modo, la transgresión de la homogamia no es sólo un asunto individual, de creencias personales o de interacciones cara a cara, pues factores externos como los indicados pueden alterar prácticas y juicios de legitimidad que antes aparecían como habituales y normales.

En definitiva, el caso expuesto en este artículo, relativo al comportamiento de las clases medias chilenas en un plano relativamente irreflexivo como la conformación de uniones de pareja, aporta al conocimiento de cómo ocurren en general los procesos de transgresión de los condicionamientos sociales que se encuentran subjetivamente establecidos.

\section{Bibliografía}

Ariès, P. y Duby, G., Historia de la vida privada, Madrid, Taurus, vol. 4, 2001.

Balmori, D. and Oppenheimer, R., "Family Clusters: Generational Nucleation in Nineteenth-Century Argentina and Chile", en Comparative Studies in Society and History, Vol. 21, No. 2, apr., 1979, pp. 231 - 261.

Balmori, D., F. Voss, S. y Wortman, M., Las alianzas de familias y la formación del país en América Latina, México DF, Fondo de Cultura Económica, 1990.

Barr-Melej, P., Reforming Chile: cultural politics, nationalism, and the rise of the middle class, Chapel Hill, University of North Carolina Press, 2000.

Barr-Melej, P., "Hippismo a la chilena: Juventud y heterodoxia cultural en un contexto transnacional (1970-1973)", Fernando Purcell, Alfredo Riquelme (eds.), Ampliando miradas: Chile y su historia en un tiempo global. Santiago, RIL Editores-Instituto de Historia PUC, 2009.

Barros Arana, D., "Revista Bibliográfica”, en Revista chilena, v. 2, 1875, pp. 364 - 376.

Beetham, D., The legitimation of power, Houndmills, Basingstoke, Macmillan, 1991.

Benítez-Rojo, A., "The nineteenth-century Spanish American novel". González Echevarría, Roberto \& Enrique Pupo-Walker, eds., The Cambridge History of Latin American Literature, Cambridge, UK, Cambridge University Press, 1996, pp. 417 - 489. 
Bianchi, S., "Emociones y best-sellers", en Anales de literatura chilena, Año 2, Diciembre, Número 2, 2001, pp. 235 - 245.

Blest Gana, A., "Discurso de incorporación a la Facultad de Filosofía y Humanidades", en Anales de la Universidad de Chile, 1861.

Boltanski, L., De la critique. Précis de sociologie de l'émancipation, Editions Gallimard, Paris, 2009.

Candina, A., Por una vida digna y decorosa. Clase media y empleados públicos en el siglo XX chileno, Santiago, Frasis, 2009.

Cánovas, R., Novela chilena, nuevas generaciones. El abordaje de los huérfanos, Santiago, Ediciones Pontificia Universidad Católica de Chile, 1997.

Carter, R. \& Sepúlveda, O., "Occupational Prestige in Santiago de Chile". The American Behavioral Scientist, Sep, 8, 1, 1964, pp. 20 - 24.

Cavieres, E. y Salinas, R., Amor, sexo y matrimonio en Chile tradicional, Valparaíso, Instituto de Historia, Universidad Católica de Valparaíso, 1991.

Celikates, R., "From Critical Social Theory to a Social Theory of Critique: On the Critique of Ideology after the Pragmatic Turn", Constellations, Volume 13, No. $1,2006$.

Chanan, M. (ed.), Chilean cinema, London, British Film Institute, 1976.

Concha, J., "Prólogo", en Blest Gana, Alberto. Martín Rivas. Novela de costumbres político-sociales, Buenos Aires, Stockcero, 2006, pp. XII - XXXIX.

Contardo, Ó., Siútico. Arribismo, abajismo y vida social en Chile, Santiago, Ediciones B, 2008.

De León, C., "Las capas medias en la sociedad chilena del siglo XIX", en Anales de la Universidad de Chile, N. 132, octubre-diciembre, 1964, pp. 51 - 95.

De los Ríos, V., "Raúl Ruiz a través del espejo: de la representación a la alegoría”, en Aiesthesis, No 47, 2010, pp. 115 - 127.

Donoso, R., Un amigo de Blest Gana: José Antonio Donoso, Santiago, Imprenta Universitaria, 1935.

Elias, N., La civilización de los padres y otros ensayos, Santa Fe de Bogotá, Norma, 1998.

Engelbert, M., "Problemas de periodización: 'modernidad', 'romanticismo' y 'realismo' en 'Martín Rivas' y 'María' ", en Alpha, N¹6, 2000, pp. 37 - 53. 
Erikson, R. and Goldthorpe, J. H., The Constant Flux, Oxford, Oxford University Press, 1993.

Espinoza, Vicente y Emmanuelle Barozet. ¿De qué hablamos cuando decimos 'clase media'? Perspectivas sobre el caso chileno, Santiago, Expansiva-UDP, en foco, $\mathrm{N}^{\circ}$ 142, 2008.

Esteve, A. \& McCaa, Robert, 2007, "Homogamia educacional en México y Brasil, 19702000: pautas y tendencias", en Latin American Research Review, Vol. 42, No. 2, pp. $56-85$.

Eyzaguirre, J., Fisonomía histórica de Chile, Santiago, Universitaria, 1978.

Filgueira, C., La actualidad de viejas temáticas: sobre los estudios de clase, estratificación y movilidad social en América Latina, Santiago, CEPAL, División de Desarrollo Social, Serie Políticas Sociales, No. 51, 2001.

Foresti, C., Löfquist, E. y Foresti, Á., La narrativa chilena. Desde la independencia hasta la Guerra del Pacífico, Santiago, Editorial Andrés Bello, vol. 2, 2001.

Franco, R. y Hopenhayn, M., "Las clases medias en América Latina: historias cruzadas y miradas diversas". Franco, Rolando, Martín Hopenhayn, Arturo León (Coordinadores), Las clases medias en América Latina. Retrospectiva y nuevas tendencias, México DF, CEPAL-Siglo XXI, 2010, pp. 7 - 39.

Franco, R., León, Arturo, Atria, R., "Estratificación y movilidad social en América Latina. Una agenda de trabajo". Franco, Rolando, Arturo León, Raúl Atria, eds., Estratificación y movilidad social en América Latina. Transformaciones estructurales de un cuarto de siglo. Santiago, LOM Ediciones, 2007, pp. 25 - 69.

García-Corrales, G., "Nostalgia versus modernidad: entrevista a Marcela Serrano". Confluencia, Vol. 13, No. 1, Fall, 1997, pp. 228 - 234.

Garretón, M. A., The socio-political matrix and economic development in Chile. Manchester, School of Environment \& Development, University of Manchester, Discussion Paper Series Number Fifteen A, October, 2007.

Gazmuri, C., El " 48 " chileno: igualitarios, reformistas radicales, masones y bomberos, Santiago, Universitaria, 1999.

Goffman, E., 1974. Frame analysis: An essay on the organization of experience. Pennsylvania: Northern University Press, 1974, reprinted 1986.

Goic, C., La novela chilena: los mitos degradados, Santiago, Universitaria, 1968.

Goicovic, I., Relaciones de solidaridad y estrategia de reproducción social en la familia popular del Chile tradicional (1750-1863), Madrid, Consejo Superior de Investigaciones Científicas, Instituto de Historia, 2006. 
González, M., De empresarios a empleados. Clase media y Estado Docente en Chile, 1810-1920, Santiago, LOM, 2011.

Guerra, L., Texto e ideología en la narrativa chilena, Minneapolis, Prisma, 1987.

Habermas, J., Teoría de la acción comunicativa, Madrid, Taurus, Vol. I, 1987.

Jocelyn-Holt, A., El peso de la noche. Nuestra frágil fortaleza histórica, Santiago, Editorial Planeta, 1999.

Johnson, A., Internal migration in Chile to 1920: its relation to the labor market, agricultural growth and urbanization, Davis, University of California, Ph. D. Dissertation. 1978.

León, A., Martínez, Javier, La estratificación social chilena hacia fines del siglo XX,Santiago: CEPAL-División de Desarrollo Social, Serie Políticas Sociales $N^{\circ} 52$, agosto de 2001.

McCaa, R., Marriage and fertility in Chile. Demographic turning points in the Petorca Valley, 1840-1976, Westview Press, Boulder, Colorado, 1983.

Melfi, D., Estudios de literatura chilena, Santiago, Nascimento, 1938.

OECD, Latin American Economic Outlook 2011. How Midle-class is Latin America? OECD Publishing, 2011.

OIT, Clasificación internacional uniforme de ocupaciones: CIUO-88. Ginebra, Oficina Internacional del Trabajo, 1991.

Salazar, G.; Pinto, J., Historia contemporánea de Chile, Santiago, LOM, Vol. 2, 1999.

Schwalbe, Michael, Sandra Godwin, Daphne Holden, Douglas Schrock, Shealy Thompson and Michelle Wolkomir. "Generic Processes in the Reproduction of Inequality: An Interactionist Analysis", Social Forces, N 79, 2000, pp. 419 - 452.

Silva Castro, R., Alberto Blest Gana: 1830-1920, Santiago, Zig-Zag, 1955.

Subercaseaux, B. Historia de las ideas y de la cultura en Chile, Santiago, Editorial Universitaria, Vol. 2, 1997.

Subercaseaux, B., Historia del libro en Chile: desde la Colonia hasta el Bicentenario, Santiago, LOM, 3a. edición, 2010.

Torche, F., Wormald, G., Estratificación y movilidad social en Chile: entre la adscripción y el logro, Santiago, CEPAL, Serie Políticas Sociales N 98, 2004. 
Torche, F., Movilidad intergeneracional y cohesión social: análisis comparado de Chile y México, Santiago, Cieplan-iFHC, Documento de trabajo, 2007.

Van Leeuwen, M.; Ineke Maas, A. M. HISCO. Historical international standard classification of occupations, Leuven, Leuven University Press, 2002.

Vicuña, M., La belle époque chilena: alta sociedad y mujeres de élite, Santiago, Catalonia, 2010. 